\title{
EXPERIMENTAL VALIDATION OF FINITE ELEMENT MODELS FOR REINFORCED CONCRETE BEAMS WITH AND WITHOUT DISCONTINUITES
}

\author{
Marios Filippoupolitis ${ }^{1}$, Carl Hopkins ${ }^{2}$ and Siu-Kui $\mathrm{Au}^{3}$ \\ ${ }^{1}$ Institute for Risk and Uncertainty, University of Liverpool \\ Liverpool, L69 7ZF, UK \\ e-mail: m.filippoupolitis@ @iverpool.ac.uk \\ ${ }^{2}$ Acoustics Research Unit, School of Architecture, University of Liverpool \\ Liverpool, L69 7ZN, UK \\ e-mail: carl.hopkins@liverpool.ac.uk \\ ${ }^{3}$ Centre of Engineering Dynamics, School of Engineering, University of Liverpool \\ Liverpool, L69 3GH, UK \\ e-mail: siukuiau@liverpool.ac.uk
}

Keywords: Reinforced Concrete Beams, Discontinuities, Finite Element Analysis, Experimental Modal Analysis, Eigenfrequencies, Validation.

\begin{abstract}
The aim of this paper is to assess the degree of accuracy in modelling the dynamic behaviour of reinforced concrete beams with and without discontinuities. Finite element models of three damaged and undamaged reinforced concrete beams were developed in Abaqus combining solid and beam elements and experimentally validated using experimental modal analysis. For the undamaged beams the agreement between the lowest 24 eigenfrequencies from the models and the measurements were within $\approx 3 \%$. For the damaged beams, the agreement was within $4 \%$ above the lowest axial mode, whereas the errors were up to $10 \%$ below the lowest axial mode. The validated finite element models will be used for further studies on the dynamic behaviour of collapsed reinforced concrete buildings.
\end{abstract}




\section{INTRODUCTION}

Every few years an earthquake of high magnitude occurs around the globe leading in collapsed structures with people trapped inside them. When victims are trapped inside a collapsed building, the challenge is to detect and locate survivors within a period of time that will allow them to be rescued. The majority of documented live rescues are accomplished within the first 5 to 6 days [1]. However, important variables affect the survivability including the structure type and void space formation, the cause of the structural collapse, the survival location in the building and the speed and sophistication of available search and rescue capabilities [2].

Airborne sound from survivors tends to be highly attenuated by layers of rubble and requires the existence of air paths for propagation to the surface. For this reason there is greater potential to detect physical movement or signals by measuring vibration due to structure borne sound (i.e. seismic research method). In a seismic search, a small number of seismic sensors are moved over a regular grid so that the operators can be certain they have searched the entire site. The placement and positioning of these sensors is critical for the successful detection of the survivors. However, grid spacing and sensor placement are often decided simply by checking whether it is possible to detect transients generated by the operators in an adjacent grid area on the surface in places where the structure is safe to walk [3]. This can be misleading because horizontal propagation of vibration across the surface of a collapsed structure is only vaguely indicative of propagation into the depths of a collapsed structure.

This research forms part of a PhD project which is funded by the EPSRC and concerns an approach to search for human survivors using structure-borne sound propagation in collapsed and fragmented structures through the development, validation and use of theoretical models. The aim in this paper is to assess the degree of accuracy in modelling the dynamic behaviour of damaged and undamaged one-dimensional reinforced concrete building elements. Experimental modal analysis is carried out on three reinforced concrete beams with and without discontinuities and the results are used for the validation of finite element models.

\section{METHODS}

\subsection{Test specimens}

The experimental samples consist of three reinforced concrete beams (C25/30, S500) with the same dimensions ( $2.4 \mathrm{~m}$ length, $0.2 \mathrm{~m}$ width and $0.3 \mathrm{~m}$ depth). The beams are reinforced with four longitudinal steel bars of $16 \mathrm{~mm}$ diameter and transverse reinforcement consisting of $8 \mathrm{~mm}$ diameter stirrups placed at $200 \mathrm{~mm}$ centres along the beams (see Figure 1). Three beams were measured: Beam 1 - an undamaged beam, Beam 2 - a beam with a $100 \mathrm{~mm}$ discontinuity in one position and Beam 3 - a beam with two $100 \mathrm{~mm}$ discontinuities in two positions. Figure 1 shows the structural details of the three reinforced concrete beams.

The discontinuities on beams 2 and 3 were formed by using a diamond saw to cut out the concrete. This also introduced cuts into some of the longitudinal steel bars which randomly reduced their cross-sectional area by 15 to $60 \%$. These cuts into the steel bars are located at the beginning and end of each discontinuity zone (see Figure 2) and increased the uncertainty in the Abaqus models.

Table 1 gives the weight of each reinforced concrete beam that was measured using a crane scale. 


\begin{tabular}{|c|c|}
\hline Beam & Weight $[\mathrm{Kg}]$ \\
\hline 1 & 352.0 \\
\hline 2 & 330.8 \\
\hline 3 & 322.6 \\
\hline
\end{tabular}

Table 1. Beam weights.

Beam 1
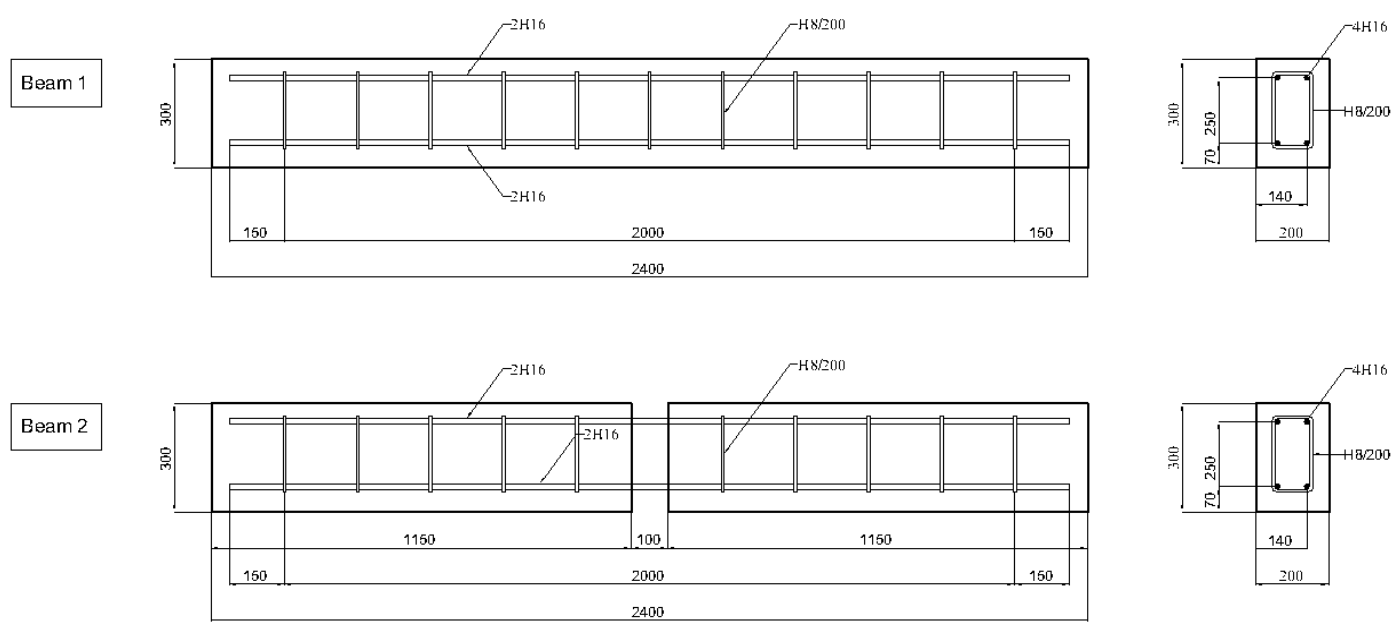

Beam 3
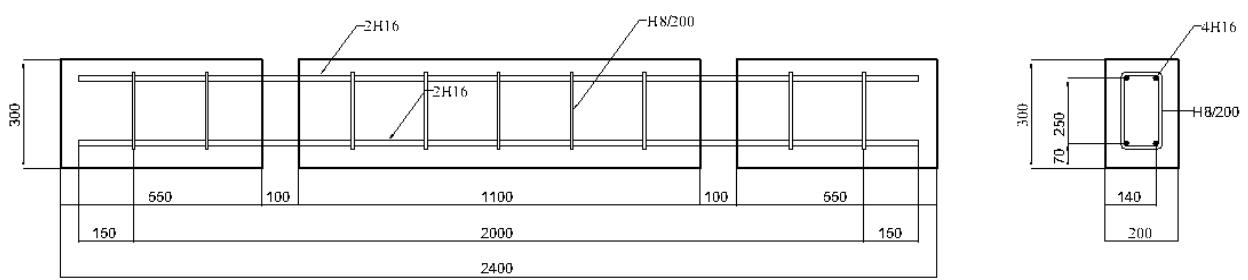

Units: mm

Figure 1. Structural details of the reinforced concrete beams.

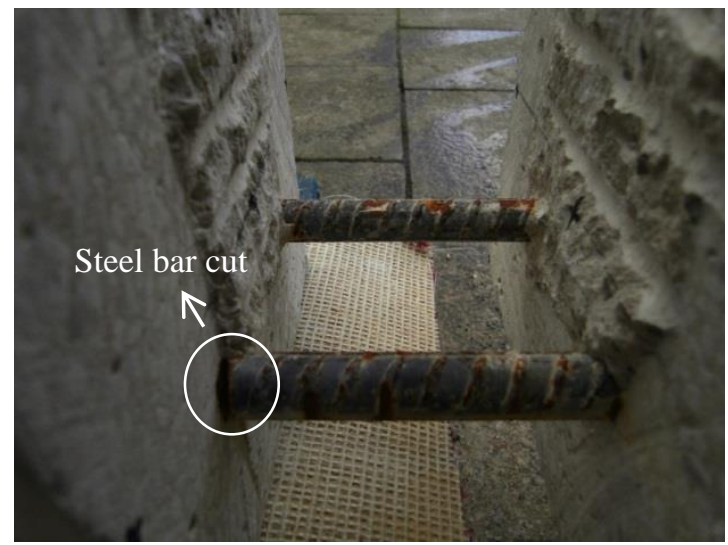

Figure 2. Example of the reduction in the cross-section of a steel bar caused by a diamond saw cut 


\subsection{Experimental work}

Experimental modal analysis was carried out on the three reinforced concrete beams in order to identify their dynamic characteristics (i.e. eigenfrequencies and modeshapes). The beams were suspended using polyester slings from an overhead crane in order to approximate a beam with free - free boundary conditions as the sling was assumed to have negligible effect on the dynamic response (Figure 3).

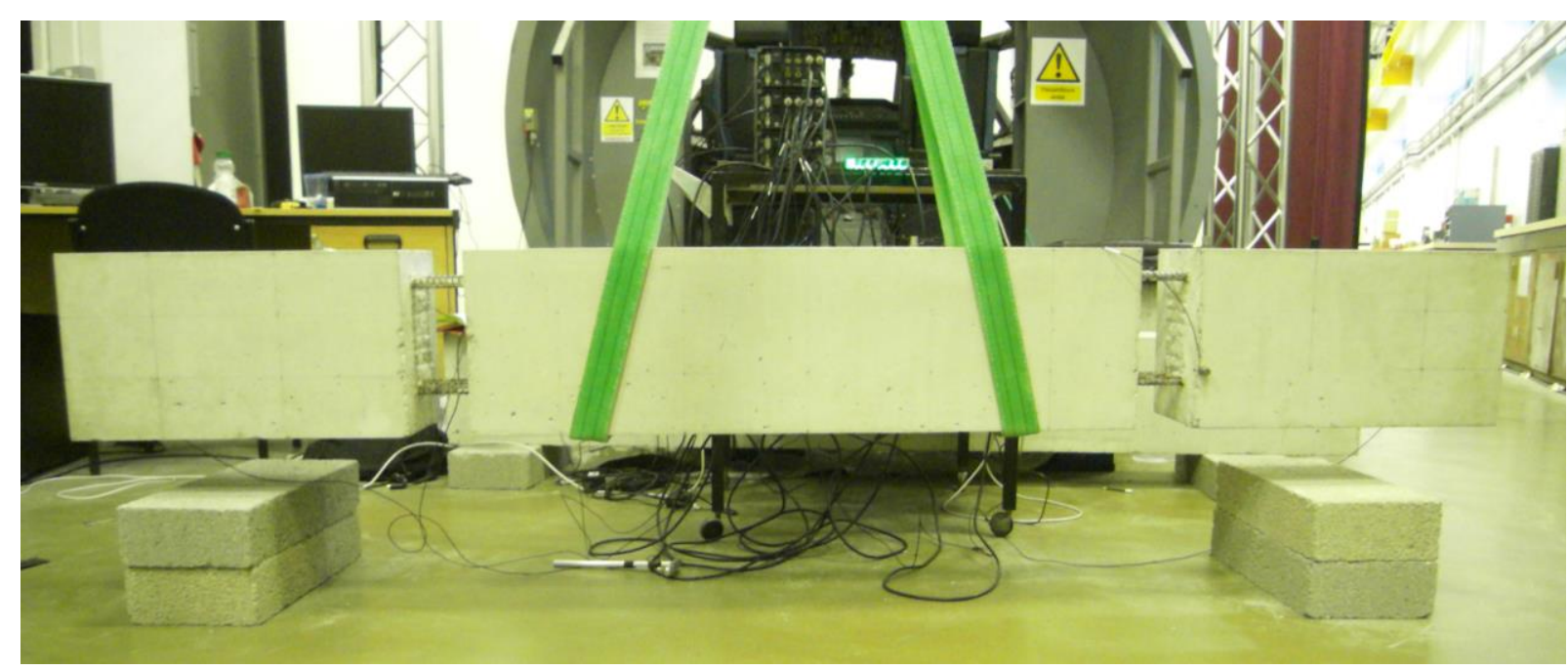

Figure 3 Test setup showing the test equipment and the polyester slings that approximate the free-free boundary condition for Beam 3

The beams were excited using a Brüel \& Kjær Type 8200 impact hammer and the response on beams 1, 2 and 3 was measured using three, six and nine Brüel \& Kjær Type 4371 accelerometers respectively. The transducers were connected to a Brüel \& Kjær Type 3050-A-060 FFT analyser via a Type 2692 Nexus Conditioning Amplifier. The commercial software Brüel \& Kjær Pulse Reflex was used for signal processing and the modal analysis. The accelerometers remained at fixed positions whilst the impact hammer was moved along a mesh of excitation points with spacing of $0.15 \mathrm{~m}$ or $0.2 \mathrm{~m}$ along the length and $0.1 \mathrm{~m}$ in the other two directions. It is noted that only the concrete parts of the beams were excited. The total number of excited degrees of freedom was 206, 244 and 282 for beams 1, 2 and 3 respectively.

\subsection{Finite element modelling}

Finite element models of the three reinforced concrete beams were developed in Abaqus [4] and eigenfrequency analysis was carried out to define their dynamic characteristics (eigenfrequencies and modeshapes).

The solid element C3D20R (20 nodes) and the beam element B32 (3 nodes) were selected from the element library of Abaqus to model the concrete and the steel bars respectively. Both elements were selected to have interpolation functions of the same order (quadratic) to avoid accuracy issues [5]. This technique of combining three-dimensional (solid) with one dimensional (truss or beam) elements for modelling reinforced concrete members is well-established in the finite element analysis literature $[6,7]$. A finite element mesh with dimensions of 25 $\mathrm{mm}$ in the longitudinal and $20 \mathrm{~mm}$ in the other two directions resulted in 27 elements per wavelength for the concrete and 8 elements per wavelength for the steel bars, at $3200 \mathrm{~Hz}$. 
This mesh density fulfils the requirement for at least 6 quadratic elements per wavelength in structural and vibroacoustic problems [8].

For the models of Beams 2 and 3 the discontinuities were formed by removing the appropriate number of solid and beam elements in each discontinuity zone (Figure 4). This approach was an efficient way of creating discontinuities in different positions of the beams without re-meshing.

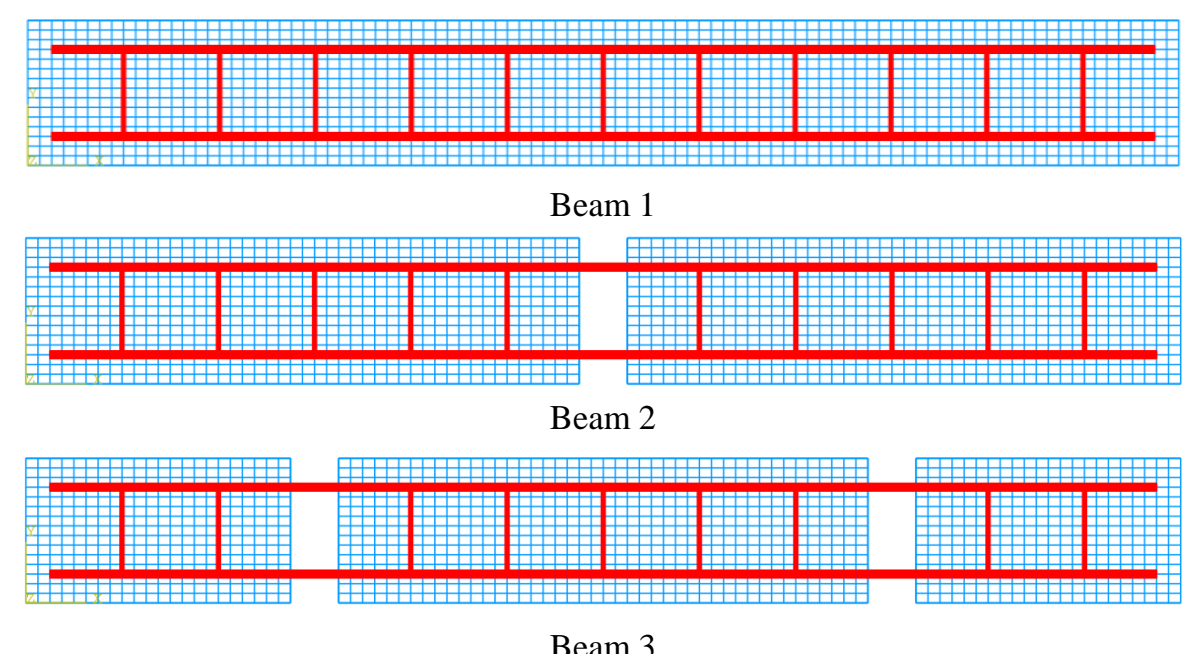

Figure 4. Finite element modeling of the reinforced concrete beams using solid and beam elements.

In order to investigate the influence of the steel cuts in the dynamic behavior of beams 2 and 3, local sectional area reduction zones of $2 \mathrm{~mm}$ length were modelled in Abaqus where generalized sections were used to approximate the profile properties.

Table 2 shows the physical and mechanical properties of the materials used in the models. The material properties of the steel and Poisson's ratio of the concrete were taken from the literature $[9,10]$. The density of the concrete for each beam was defined by dividing the weight of the beams by their volume after extracting the weight of the steel reinforcement.

The Young's modulus of the concrete, $E_{c}$ was estimated after model updating against the experimental results. Numerical trials with different Young's modulus, $E_{c}$ were carried out for beam 1 up to the stage where the first numerical eigenmode had $0 \%$ difference against the first experimental eigenmode in terms of eigenfrequencies. The estimated value of the Young's modulus is relatively high but it is inside the range that is proposed in the literature for $\mathrm{C} 25 / 30$ concrete [11].

\begin{tabular}{|c|c|c|c|c|}
\hline \multirow{2}{*}{ Material } & \multicolumn{2}{|c|}{ Density, $\rho\left[\mathrm{Kg} / \mathrm{m}^{3}\right]$} & $\begin{array}{c}\text { Young's } \\
\text { modulus, } \\
E\left[\mathrm{~N} / \mathrm{m}^{2}\right]\end{array}$ & $\begin{array}{c}\text { Poisson's } \\
\text { ratio, } v\end{array}$ \\
\hline \multirow{3}{*}{ Concrete } & Beam 1 & 2328.7 & & \\
\cline { 2 - 3 } & Beam 2 & 2277.8 & $36875 \mathrm{E} 06$ & 0.2 \\
\cline { 2 - 3 } & Beam 3 & 2320.8 & & \\
\hline Steel & \multicolumn{2}{|c|}{7800} & $200 \mathrm{E} 09$ & 0.3 \\
\hline
\end{tabular}

Table 2. Material properties. 


\section{RESULTS}

In this section the mode pairs are characterized according to their mode shape as being either bending (B), torsional (T) or axial (A) modes. Table 3 compares the results of the finite element analysis against the experimental results for Beam 1 in terms of eigenfrequencies.

\begin{tabular}{|c|c|c|c|c|}
\hline $\begin{array}{c}\text { Mode } \\
\text { type }\end{array}$ & $\begin{array}{c}\text { Mode } \\
\text { pair }\end{array}$ & $\begin{array}{c}\text { Experimental modal } \\
\text { analysis } \\
{[\mathrm{Hz}]}\end{array}$ & $\begin{array}{c}\text { FEM } \\
{[\mathrm{Hz}]}\end{array}$ & $\begin{array}{c}\text { Difference } \\
{[\%]}\end{array}$ \\
\hline B & 1 & 138.19 & 138.19 & 0.00 \\
\hline B & 2 & 209.57 & 205.59 & 1.90 \\
\hline B & 3 & 366.30 & 365.72 & 0.16 \\
\hline T & 4 & 447.96 & 446.14 & 0.41 \\
\hline B & 5 & 529.20 & 521.30 & 1.49 \\
\hline B & 6 & 684.87 & 680.10 & 0.70 \\
\hline A & 7 & 861.64 & 838.87 & 2.64 \\
\hline T & 8 & 896.33 & 892.54 & 0.42 \\
\hline B & 9 & 944.14 & 927.07 & 1.81 \\
\hline B & 10 & 1069.14 & 1057.70 & 1.07 \\
\hline T & 11 & 1343.43 & 1339.40 & 0.30 \\
\hline B & 12 & 1408.26 & 1382.50 & 1.83 \\
\hline B & 13 & 1499.09 & 1480.10 & 1.27 \\
\hline A & 14 & 1721.10 & 1675.70 & 2.64 \\
\hline T & 15 & 1799.68 & 1787.00 & 0.70 \\
\hline B & 16 & 1902.95 & 1864.40 & 2.03 \\
\hline B & 17 & 1961.47 & 1933.30 & 1.44 \\
\hline T & 18 & 2253.04 & 2235.30 & 0.79 \\
\hline B & 19 & 2410.26 & 2358.00 & 2.17 \\
\hline B & 20 & 2451.17 & 2407.00 & 1.80 \\
\hline A & 21 & 2577.19 & 2507.70 & 2.70 \\
\hline T & 22 & 2709.78 & 2684.40 & 0.94 \\
\hline B & 23 & 2920.24 & 2853.10 & 2.30 \\
\hline B & 24 & 2948.11 & 2893.70 & 1.85 \\
\hline & & & & \\
\hline
\end{tabular}

Table 3. Comparison between experimental modal analysis and FEM in terms of eigenfrequencies - Type A1 beam. (B, T and A correspond to bending, torsional and axial modes respectively).

Figure 5 and Figure 6 show the percentage difference between experimental and FEM eigenfrequencies for the 26 and 28 mode pairs of beams 2 and 3 respectively. 


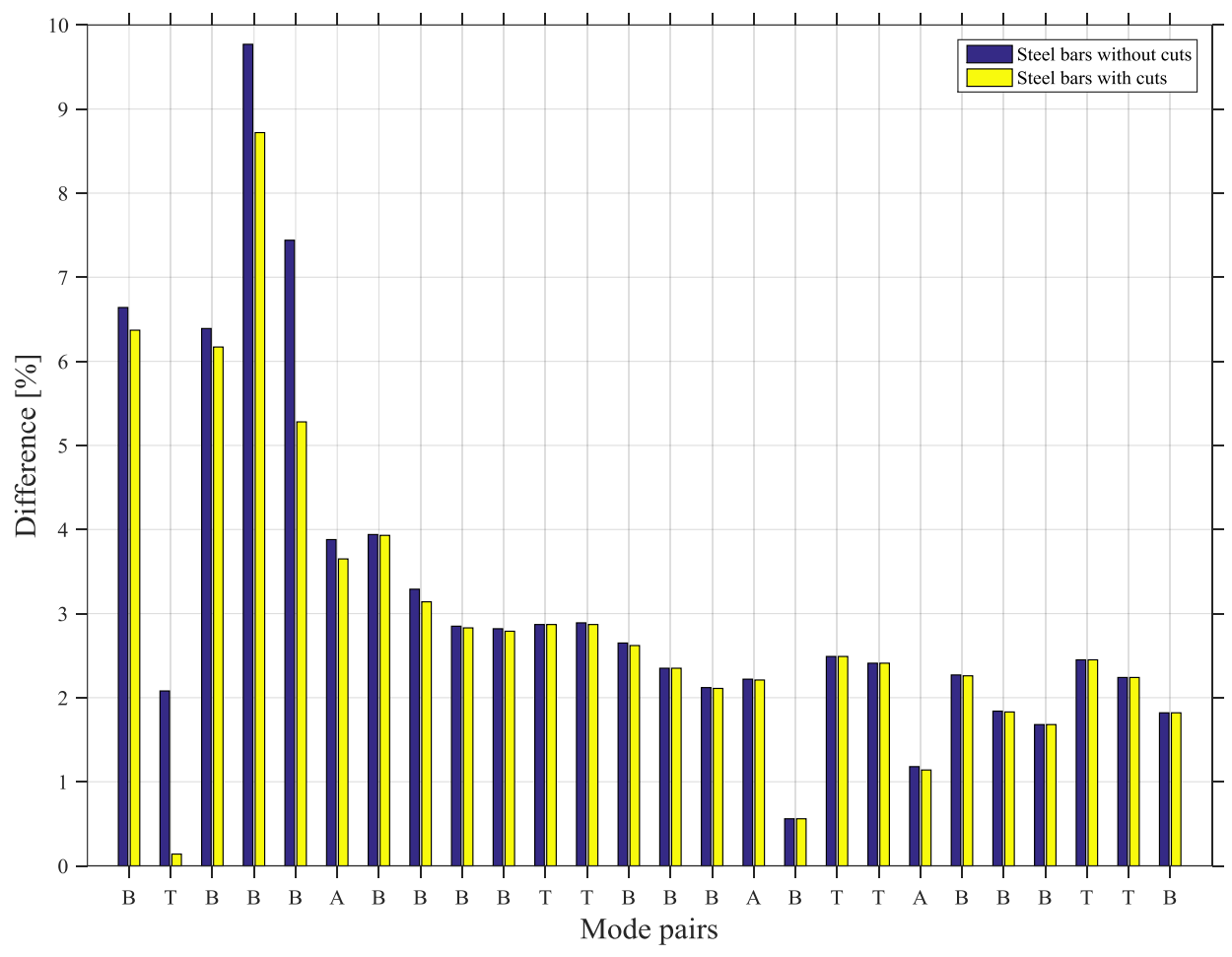

Figure 5. Percentage difference between FEM and experimental eigenfrequencies for beam 2 (B, T and A correspond to bending, torsional and axial modes respectively). Modes are ordered from the lowest to the highest eigenfrequency from left to right.

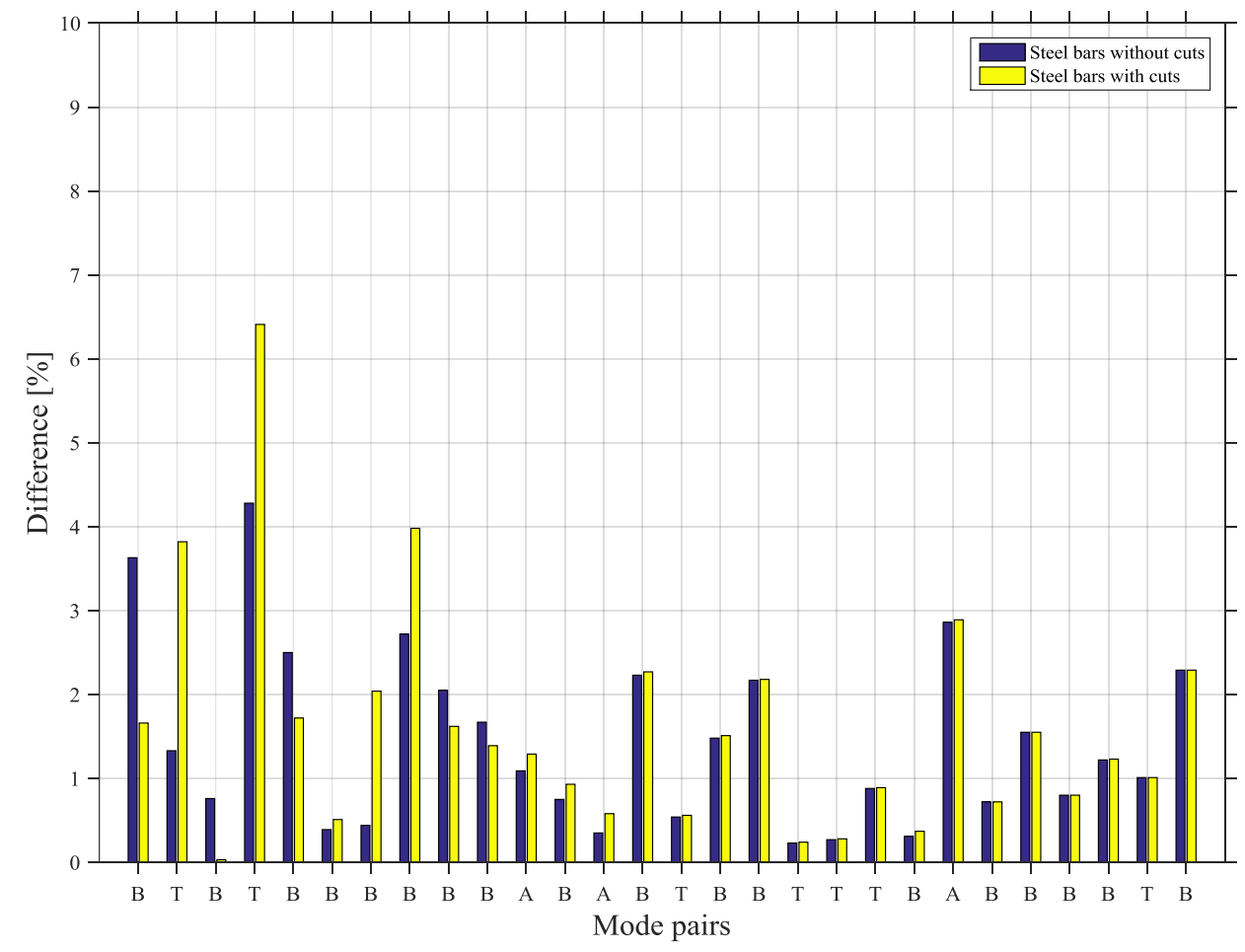

Figure 6. Percentage difference between FEM and experimental eigenfrequencies for beam 3 (B, T and A correspond to bending, torsional and axial modes respectively). Modes are ordered from the lowest to the highest eigenfrequency from left to right. 


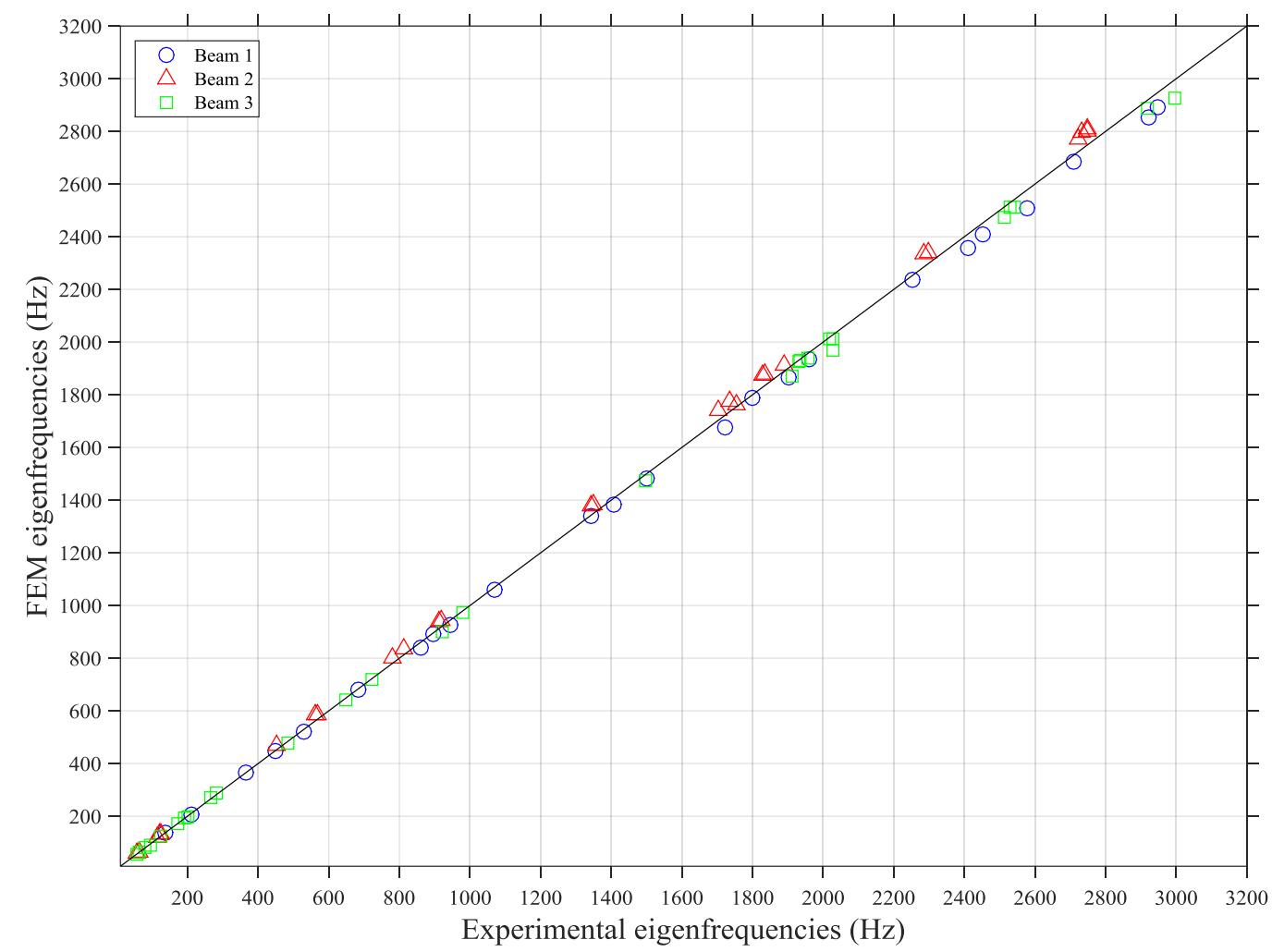

Figure 7. Comparison between experimental and FEM eigenfrequencies for beams 1, 2 and 3.

\section{ANALYSIS AND DISCUSSION}

In general, close agreement was achieved between FEM and experimental eigenfrequencies for all three reinforced concrete beams as indicated in Figure 7. Therefore the number of discontinuities did not significantly affect the accuracy of the finite element models in terms of their eigenfrequencies.

For beam 1, close agreement was achieved between FEM and experimental results (see Table 3). All the mode pairs in the frequency range from 1 to $3200 \mathrm{~Hz}$ had differences less than $3 \%$ in terms of eigenfrequencies.

For beam 2, all the 21 mode pairs above the first axial mode $(450.9 \mathrm{~Hz})$ and mode pair 2 , showed close agreement between FEM and the experimental results with differences in the eigenfrequencies of less than $4.0 \%$ (see Figure 5). Higher differences occurred with mode pairs 1, 3, 4 and 5 with differences between 6 and $10 \%$.

For beam 3, close agreement was achieved between FEM and experimental results for all the mode pairs in the frequency range from 1 to $3200 \mathrm{~Hz}$ with differences less than $5 \%$ (see Figure 6). Apart from mode pairs 1 and 4 the other pairs all showed differences below $3 \%$.

The effect of including the diamond saw cuts to the reinforcement bars in the FEM model of beams 2 and 3 was negligible above the first axial mode. Figure 5 and Figure 6 show that in the models with the discontinuities, the steel cuts mainly affect the modes before the first axial mode. Modelling the steel cuts improved the agreement between FEM and experimental results for beam 2 while it is not clear that including the steel cuts had a significant effect for beam 3 . 


\section{CONCLUSIONS}

Experimental work has quantified the material properties and the dynamic behavior of three reinforced concrete beams with and without discontinuities. These represent undamaged and damaged beams as might occur in a building after an earthquake.

Finite element models have been successfully validated against experimental modal analysis for these three beams. It was shown that the number of discontinuities did not significantly affect the accuracy of the predicted eigenfrequencies. For the undamaged beams the agreement between the lowest 24 eigenfrequencies from the models and the measurements were within $\approx 3 \%$. For the damaged beams, the agreement was within $4 \%$ above the lowest axial mode, whereas the errors were up to $10 \%$ below the lowest axial mode.

An efficient and accurate method of creating discontinuities was experimentally validated. This will inform later stages of the work where numerical experiments will be carried out to assess the influence that various patterns of discontinuities have in the dynamic behavior of one dimensional reinforced concrete members. This will allow Monte Carlo simulations to incorporate aspects of uncertainty that would exist in real fragmented buildings.

\section{ACKNOWLEDGMENT}

The authors are grateful for the funding provided by the EPSRC and ESRC Centre for Doctoral Training in Quantification Management of Risk \& Uncertainty in Complex Systems and Environments at the University of Liverpool.

\section{REFERENCES}

[1] A. G. Macintyre, J. A. Barbera and E. R. Smith, "Surviving Collapsed Structure Entrapment after Earthquakes: A "Time-to-Rescue" Analysis," Prehospital and Disaster Medicine, vol. 21, no. 1, pp. 4-19, 2006.

[2] A. G. Macintyre, J. A. Barbera and B. P. Petinaux, "Survival Interval in Earthquake Entrapments: Research Findings Reinforced During the 2010 Haiti Earthquake Response," Disaster Medicine and Public Health Preparedness, vol. 5, no. 1, pp. 13-22, 2011.

[3] C.-J. Bäckström and N. Christofferson, "Urban search and rescue - an evaluation of technical search equipment and methods," Lund University, Lund, 2006.

[4] D. Hibbitt, B. Karlsson and P. Sorensen, Abaqus 6.12 Documentation and User Manual., Providence, Rhode Island, USA: Dessault Systemes Simulia Corp, 2012.

[5] D. V. Hutton, Fundamentals of Finite Element Analysis, New York: McGraw-Hill, 2004.

[6] G. C. Lykidis and K. V. Spiliopoulos, "3D Solid Finite Element Analysis of Cyclically Loaded RC Structures Allowing Embedded Reinforcement Slippage," Journal of Structural Engineering, vol. 134, no. 4, pp. 629 - 638, 2008.

[7] T. Potisuk, C. C. Higgins, T. H. Miller and S. C. Yim, "Finite Element Analysis of Reinforced Concrete Beams with Corrosion Subjected to Shear," Advances in Civil Engineering, vol. 2011, p. 14, 2011. 
[8] N. Atalla and F. Sgard, Finite Element and Boundary Methods on Structural Acoustics and Vibration, Boca Raton: CRC Press, Taylor \& Francis Group, 2015.

[9] C. Hopkins, Sound Insulation, 1st ed., Amsterdam: Elsevier/Butterworth-Heinemann, 2007.

[10] B. Mosley, J. Bungey and R. Hulse, Reinforced Concrete Design to Eurocode 2, New York: Palgrave Macmillan, 2012.

[11] P. Bamforth, D. Chisholm, J. Gibbs and T. Harrison, "Properties of Concrete for use in Eurocode 2," The Concrete Centre, Surrey, 2008. 